www.jmscr.igmpublication.org

Index Copernicus Value: 79.54

ISSN (e)-2347-176x ISSN (p) 2455-0450

crossrefDOI: https://dx.doi.org/10.18535/jmscr/v7i3.128

Journal Of Medical Science And Clinical Research

IGM Publication

An Official Publication of IGM Publication

\title{
A Study on Effect of Routine Resection of Illioinguinal Nerve during Repair of Iguinal Hernia
}

\author{
Authors \\ Dr Sudarsan Sethy ${ }^{1^{*}}$, Dr Bikash Chandra Pal ${ }^{2}$ \\ ${ }^{1}$ Assistant Professor, Department of General Surgery, VIMSAR, Burla \\ ${ }^{2}$ Junior Resident, Department of General Surgery, VIMSAR, Burla \\ *Corresponding Author \\ Dr Sudarshan Sethy
}

\begin{abstract}
Introduction: Chronic pain following Lichtenstein repair of inguinal hernia surgery has incidence of 6 $29 \%$ and has emerged as a common and sometimes severe problem that can significantly affect a patient's health-related quality of life. It occurs due to entrapment, ligation, neuroma or fibrotic reactions involving any of the nerves at inguinal region of which the ilioinguinal nerve is most commonly involved. Though the excision of ilioinguinal nerve should theoretically eliminate the possibility of inguinal neuralgia, this concept of routine ilioinguinal nerve excision in inguinal hernia repairs is not well accepted. The present study was done with the aim to compare and correlate the therapeutic effectiveness of routine ilioinguinal neurectomyin chronic inguinodynia.

Materials and Methods: A total of 50 patients were admitted or primary inguinal hernia repair (unilateral or bilateral), satisfying all the inclusion criteria in the study. All patients were treated with Lichtenstein tension-free hernioplasty with polypropelene mesh. In one group of 25 patients, i.e (Group-A) Ilioinguinal nerve was identified and excised. In another group of 25 patients i.e. (Group-B) ilioinguinal nerve preserved. Post-operative assessment for chronic groin pain and numbness was carried out at 1 month, 6 month and 1 year. At the end of the study both the group of patients i.e. nerve excision group (group- $A$ ) and nerve preservation group (group-B) were compared forincidence of post-herniorrhaphy groin pain \& post herniorrhaphy groin numbness.

Observations: This prospective study showed a satisfactory decrease in the incidence of post-operative groin pain at 1 month, 6 months and 1 year, for patients in the ilioinguinal nerve excision group versus nerve preservation group. This study also clearly demonstrated that, elective excision of ilioinguinal nerve is not accompanied by a significant increase in post-operative groin numbness.

Conclusion: The result of this prospective trial demonstrates that prophylactic excision of ilioinguinal nerve during Lichtenstein tension free hernioplasty significantly decreases the incidence of chronic groin pain and not associated with additional morbidities in terms of local cutaneous neurosensory disturbances and ilioinguinal neurectomy should be considered as a routine surgical step during open mesh hernia repairs.
\end{abstract}

\section{Introduction}

Hernia may be defined as "protrusion of a viscus or part of a viscus through an abnormal opening in the walls of its containing cavity." ${ }^{,[1]}$ Among all the verities the external abdominal hernia is the most common form, the most frequent varieties 
being the inguinal, femoral and umbilical, accounting for $75 \%$ of cases. Lichtenstein tension free mesh hernia repair is the surgery of choice in inguinal hernia. As far as patient outcomes are concerned recently chronic groin pain has replaced recurrence as the primary complication after open inguinal hernia repair. Chronic pain following surgery has emerged as a common and sometimes severe problem that can significantly affect a patient's health-related quality of life requiring numerous interventions for treatment like local anaesthetics injections, physical therapy, multiple pain medications and / or additional surgery even removal of mesh, emphasising how difficult and challenging its management is.

Chronic post herniorrhaphy groin pain is defined as pain lasting > 3 months after surgery that occurs with greater frequency than previously thought. ${ }^{[2]}$ Incidence of long term (= 1 year) postoperative neuralgia reported for Lichtenstein repair of inguinal hernia range from 6 - 29\%.[3,4] A review of publications between 1987 to 2000 shows an overall incidence of $25 \%$ with $10 \%$ of patients having pain fitting definition of moderate or severe. ${ }^{[5]}$

Nowadays "inguinodynia" is the recommended generic term for chronic groin pain after hernia repair and it replacesterms like neuralgia or mesh inguinodynia. $^{[6]}$ It occurs due to entrapment, ligation, neuroma or fibrotic reactions involving any of these three nerves: ilioinguinal nerve, iliohypogastric nerve and the genital branches of the genitofemoral nerve, of which the ilioinguinal nerve is most commonly involved. Though the excision of ilioinguinal nerve should theoretically eliminate the possibility of inguinal neuralgia, this concept of routine ilioinguinal nerve excision in inguinal hernia repairs is not well accepted. ${ }^{[7,8]}$

The present study was done with the aim to compare and correlate the therapeutic effectiveness of routine ilioinguinal neurectomy versus nerve preservation in Lichtenstein inguinal hernia repair with respect to chronic postoperative groin pain and post-operative paraesthesia.

\section{Materials and Methods}

The study was conducted in the Department of General Surgery VIMSAR, Burla during the period from October 2016 to September 2018.

Study Group:

50 patients were randomly selected who met the inclusion criteria.

\section{Inclusion Criteria}

1. Age: 20-80 years.

2. Males

\section{Exclusion Criteria}

1. Recurrent hernia.

2. Irreducible/Strangulated hernia

3. Patients with Previous h/o stroke, Peripheral neuropathy, neuromuscular diseases, Diabetes mellitus. As from such patients no definite conclusion about pain or paraesthesia can be made

4. Patients having Pre-operative inguinal neuralgia

All the patients were divided in to 2 groups based on routine excision of ilioinguinal nerve (Group A) \& preservation of ilioinguinal nerve (Group B). Principles Followed During The Study:

1. All patients received the standard technique of hernia repair i.e. Lichtenstein's tension free hernioplasty using polypropelene mesh.

2. All repairs had been performed by one surgeon (Guide of the study) and by the same technique every time.

3. Ilioinguinal nerve was identified just after entering the inguinal canal.

4. All the patients were divided in to 2 groups based on routine excision of ilioinguinal nerve (Group A) \& preservation of ilioinguinal nerve (Group B).

5. In Group A Patient

- Ilioinguinal nerve was excised as far lateral to the deep ring as possible \& medially to where it entered rectus muscle.

- The cut ends were left alone without ligation. 
- The nerve piece was sent for histopathological confirmation of complete excision.

6. In Group B Patients

- In 21 pateints the ilioinguinal nerve was identified and preserved and in 4 patients the nerve could not be identified and were counted in nerve preservation group.

The patients were followed strictly during hospital stay. The Stitches were removed on 7th day postop and discharged with following advice

1. Avoid strenuous work for 3 months

2. Come for routine check-up after one month at SOPD positively.

3. To report any discomfort, pain, or numbness at the site of operation

Post-Operative Assessment:

1. Through personal interview \& clinical examination at 1 month routine postoperative check-up at our surgery OPD.

2. Through telephone at 6 month, and at 1 year Post-operatively

Out comes evaluated are:

1. Chronic post herniorrhaphy groin pain

a. Mild pain

i. Occasional pain or discomfort.

ii. Does not limit activity.

iii. Return to pre hernia life style.

b. Moderate pain.

i. Prevents return to normal preoperative activities such as sports \& lifting

ii. Analgesics rarely being needed.

c. Severe pain.

i. Incapacitating

ii. Interferes with activity of daily living

iii. Frequent need of analgesics

2. Paresthesia (Numbness) as told by the patients

a. In this present study patients were not aware of excision of ilioinguinal nerve.
At the end of the study both the group of patientsi.e nerve excision group (group-A) and nerve preservation group (group-B) were compared for

1. Incidence of post herniorrhaphy groin pain.

2. Incidence of post herniorrhaphy numbness.

\section{Observations}

Table No.1: Demography

\begin{tabular}{|l|c|c|}
\hline 1 & $\begin{array}{c}\text { Total number of } \\
\text { patients }\end{array}$ & 50 \\
\hline 2 & Sex (all males) & 50 \\
\hline 3 & age & $20-80$ yrs \\
\hline 5 & $\begin{array}{c}\text { Number of patients } \\
\text { available at 1 month } \\
\text { follow up }\end{array}$ & $\begin{array}{c}25 \text { (group A),25 } \\
\text { (Group B) }\end{array}$ \\
\hline 6 & $\begin{array}{c}\text { Number of patients } \\
\text { available at 6 month } \\
\text { follow up }\end{array}$ & $\begin{array}{c}24 \text { (group A),22 } \\
\text { (Group B) }\end{array}$ \\
\hline $\begin{array}{c}\text { Number of patients } \\
\text { available at 1 year } \\
\text { follow up }\end{array}$ & 24 (group A),22 \\
(Group B)
\end{tabular}

Table no. 2: Overall incidence of chronic groin pain in our prospective study.

\begin{tabular}{|l|c|c|}
\hline $\begin{array}{l}\text { Follow up } \\
\text { period }\end{array}$ & $\begin{array}{c}\text { Nerve excision } \\
\text { Group A }\end{array}$ & $\begin{array}{c}\text { Nerve preservation } \\
\text { Group B }\end{array}$ \\
\hline 1 month & $16 \%$ & $24 \%$ \\
\hline 6 month & $12.4 \%$ & $22.7 \%$ \\
\hline 1 year & $4.16 \%$ & $22.7 \%$ \\
\hline
\end{tabular}

Table-no. 3: Incidence of postoperative paraesthesia (numbness) over groin

\begin{tabular}{|l|c|c|}
\hline $\begin{array}{l}\text { Follow up } \\
\text { period }\end{array}$ & $\begin{array}{c}\text { Nerve excision } \\
\text { Group A }\end{array}$ & $\begin{array}{c}\text { Nerve preservation } \\
\text { Group B }\end{array}$ \\
\hline 1 month & $5 / 25(20 \%)$ & $3 / 25(12 \%)$ \\
\hline 6 month & $4 / 24(16.64 \%)$ & $2 / 22(9.08 \%)$ \\
\hline 1 year & $3 / 24(12.48 \%)$ & $2 / 22(9.08 \%)$ \\
\hline
\end{tabular}

Table no. 4: Incidence of Post-operative groin pain at 1 month

\begin{tabular}{|l|c|c|}
\hline Pain & $\begin{array}{c}\text { Nerve excision } \\
\text { group A }(\mathrm{n}=25)\end{array}$ & $\begin{array}{c}\text { Nerve preservation } \\
\text { groupB }(\mathrm{n}=25)\end{array}$ \\
\hline $\begin{array}{l}\text { PRESENCE OF } \\
\text { PAIN }\end{array}$ & $4(16 \%)$ & $6(24 \%)$ \\
\hline MILD PAIN & $2(8 \%)$ & $4(16 \%)$ \\
\hline MODERATE PAIN & $2(8 \%)$ & $2(8 \%)$ \\
\hline SEVERE PAIN & $0(0 \%)$ & $0(0 \%)$ \\
\hline
\end{tabular}


Table-no. 5: Incidence of post-operative groin pain at 6 month

\begin{tabular}{|l|c|c|}
\hline Pain & $\begin{array}{c}\text { Nerve excision } \\
\text { group A }(\mathrm{n}=24)\end{array}$ & $\begin{array}{c}\text { Nerve preservation } \\
\text { Group B }(\mathrm{n}=22)\end{array}$ \\
\hline $\begin{array}{l}\text { PRESENCE OF } \\
\text { PAIN }\end{array}$ & $3(12.4 \%)$ & $5(22.7 \%)$ \\
\hline MILD PAIN & $2(8.32 \%)$ & $3(13.62 \%)$ \\
\hline $\begin{array}{l}\text { MODERATE } \\
\text { PAIN }\end{array}$ & $1(4.16 \%)$ & $2(9.08 \%)$ \\
\hline SEVERE PAIN & $0(0 \%)$ & $0(0 \%)$ \\
\hline
\end{tabular}

Table no.6: Incidence of post-operative groin pain at 1 year

\begin{tabular}{|l|c|c|}
\hline Pain & $\begin{array}{c}\text { Nerve excision } \\
\text { group A }(\mathrm{n}=25)\end{array}$ & $\begin{array}{c}\text { Nerve preservation } \\
\text { groupB }(\mathrm{n}=25)\end{array}$ \\
\hline $\begin{array}{l}\text { PRESENCE OF } \\
\text { PAIN }\end{array}$ & $1(4.16 \%)$ & $5(22.7 \%)$ \\
\hline MILD PAIN & $1(4.16 \%)$ & $4(18.16 \%)$ \\
\hline $\begin{array}{l}\text { MODERATE } \\
\text { PAIN }\end{array}$ & $0(0 \%)$ & $1(4.54 \%)$ \\
\hline SEVERE PAIN & $0(0 \%)$ & $0(0 \%)$ \\
\hline
\end{tabular}

\section{Discussion}

Chronic groin pain following inguinal hernia (hermionhaphy/hernioplasty) is becoming a significant clinical problem both for the patients and surgeons. In open methods of hernia repair, the Lichtenstein tension free herniorrhaphy" regarded as the gold standard, affordable \& acceptable to all economic class of people. The low recurrence rate $(0-1 \%)$ in these procedures shifted the hernia surgeon's attention from recurrence to chronic groin pain syndrome. Some times in our surgical OPD, patients comes with complain of groin pain, after a hernia operation performed elsewhere.

First of all, it is important to differentiate chronic pain from acute pain. Early postoperative pain easily and successfully managed with analgesics and generally resolves within 15 to 30 days of surgery without the need of further treatment.

On the contrary, moderate to severe chronic pain,

1. Generally seen 3 months after surgery.

2. A potentially debilitating condition (patient unable to perform daily activities or to return to work).

3. Usually refractory to analgesics

3. Successfully treated only by surgical interventions like neurectomy, neuronolysis, and excision of the neuroma and even removal of the mesh.

This complication is more frequent than would appear from reports in literature, with the incidence increasing in recent years.

Incidence of long term (1 year) chronic groin pain, reported after Lichtenstein repair of inguinal hernia ranges from 5 to $50 \%$ according to different studies

Table no.7: Incidence of chronic groin pain (postoperative) in various studies.

\begin{tabular}{|l|c|c|}
\hline Sl.No & Authors & $\begin{array}{c}\text { Incidence of chronic groin } \\
\text { pain (post-operative) }\end{array}$ \\
\hline 1 & $\begin{array}{c}\text { Poobalanetal } \\
(2001)[9]\end{array}$ & $30 \%$ \\
\hline 2 & $\begin{array}{c}\text { Poobalanetal } \\
(2003)[5]\end{array}$ & $54 \%$ \\
\hline 3 & $\begin{array}{c}\text { Bay-Nielsen etal } \\
(2004)[10]\end{array}$ & $22.9 \%$ \\
\hline 4 & $\begin{array}{c}\text { Alfierisetal } \\
(2006)[11]\end{array}$ & $41 \%(6 \mathrm{~m})$ \\
\hline 5 & $\begin{array}{c}\text { Dennis etal (2007) } \\
{[12]}\end{array}$ & $58 \%$ \\
\hline 6 & $\begin{array}{c}\text { Dannis Hernia Data } \\
\text { Base Group }\end{array}$ & $29 \%$ \\
\hline
\end{tabular}

The variability of this range may also depend on the definition of pain and timing of pain.

In the present study we have evaluated chronic groin pain at 1 month, 6 months and 1 year follow up $\&$ chronic pain is defined as "pain persisting beyond the normal tissue healing time, assumed to be 3 months". Several factors have been proposed as predictors of chronic pain, however, the pathogenic aspects of chronic pain are still unknown and only hypothesized. Proposed mechanisms for development of chronic pain $\operatorname{are}^{[13]}$ :

1. Inflammation and fibrosis induced by the mesh, which is in close proximity to ilioinguinal nerve (Nerve entrapment).

2. Unintentional injury during surgery.

- Partial division.

- Contusion.

○ Crushing.

- Electrical injury during coagulation.

- Strangulation of ilioinguinal nerve during suturing.

3. Neuroma formation. 
There is increasing evidence to suggest that prophylactic excision of ilioinguinal nerve during open hernia repair is not only associated with minimal morbidities but also can potentially decrease the incidence of chronic groin pain following operation.

The first randomized control trial to address this problem was by Ravichandran et al.(2000) by comparing preservation or division of ilioinguinal nerve in inguinal hernia repair. 20 patients with bilateral hernia were randomized to nerve preservation on one side and division on the other. [14]

Table no.8: Post-operative chronic groin pain \& numbness at 6 months, Ravichandranetal

\begin{tabular}{|l|c|c|}
\hline & $\begin{array}{c}\text { Group-A } \\
\text { (Nerve } \\
\text { division) }\end{array}$ & $\begin{array}{c}\text { Group-B } \\
\text { (Nerve } \\
\text { preservation) }\end{array}$ \\
\hline $\begin{array}{l}\text { Post-operative } \\
\text { chronic groin pain }\end{array}$ & $0 / 20(0 \%)$ & $1 / 20(5 \%)$ \\
\hline Numbness & $2 / 20(10 \%)$ & $0 / 20(0 \%)$ \\
\hline
\end{tabular}

These differences were all non-significant and no definite conclusions could be made.

Tsakayanis et al (2004) in a prospective review of 191 patients who underwent elective excision of ilioinguinal nerve during open, tension free" inguinal hernia repair, and they showed none of the patient developed chronic pain at 12 month of follow-up, numbness was found in $9.42 \%$ (1 month) and $6.28 \%$ (after 1 year). ${ }^{[15]}$

In another retrospective study, Dittrick et al (2004), reported a significantly lower incidence of chronic groin pain in ilioinguinal neurectomy group when compared with nerve preservation group. Nerve excision group was not accompanied by significant increase in an operative paresthesia. [16]

Table no.9: Dittrick et al (2004)

\begin{tabular}{|l|c|c|c|c|}
\hline \multirow{2}{*}{} & \multicolumn{2}{|c|}{$\begin{array}{c}\text { Post-operative chronic } \\
\text { groin pain }\end{array}$} & \multicolumn{2}{c|}{$\begin{array}{c}\text { Post-operative } \\
\text { Paresthesia }\end{array}$} \\
\cline { 2 - 5 } & $\begin{array}{c}\text { Nerve } \\
\text { excision }\end{array}$ & $\begin{array}{c}\text { Nerve } \\
\text { preservation }\end{array}$ & $\begin{array}{c}\text { Nerve } \\
\text { excison }\end{array}$ & $\begin{array}{c}\text { Nerve } \\
\text { preservation }\end{array}$ \\
\hline 1 month & $5 \%$ & $21 \%$ & $20 \%$ & $4 \%$ \\
\hline 6 month & $3 \%$ & $26 \%$ & $18 \%$ & $4 \%$ \\
\hline 1 year & $3 \%$ & $25 \%$ & $13 \%$ & $5 \%$ \\
\hline
\end{tabular}

Furthermore, there was a consistent decrease in incidence of paraesthesia with time. This may suggest progressive compensation from adjacent sensory nerve that could continue to improve over time.

Bansal et al (2009) ${ }^{[17]}$ reported that pain was not a significant complaint at 1 month. At 6 months, 1 (4\%) patient had mild pain and $2(8 \%)$ patients moderate pain in nerve preservation group and none had pain in nerve excision group. Numbness was higher in nerve excision group (12 patients) than in nerve preservation group ( 9 patients) (48\% versus $36 \%$ ) after 1 month of follow-up.

Mulkipatil et al. (2017) ${ }^{[18]}$ found that, in the two groups(nerve excision v/s nerve preservation group) the incidence of post-operative severe pain was $36 \%$ versus $6 \%$ at POD-1, moderate pain $94 \%$ versus $22 \%$ at POD-3, moderate pain $78 \%$ versus $10 \%$ at POD-7 and no pain $8 \%$ versus $35 \%$ after 1 month of surgery respectively. Incidence of post-operative hypoesthesia and numbness at groin between the two groups at all post-operative follow up was found to be non-significant.

Belagali et al.(2018) ${ }^{[19]}$ in their study of 60 patients with 30 patients each in nerve excision group and nerve preservation group found during vigorous activities, more group $B$ patients had pain compared to group A patients at 4-month [5 (17\%) vs. 15 (50\%); p=0.006; Chisquare test] and 8-month follow-up $\left[\begin{array}{lllll}4 & (13 \%) & \mathrm{v} / \mathrm{s} & 11 & (37 \%)\end{array}\right.$ $; \mathrm{p}=0.04]$

However, these results were not confirmed in a recent randomized controlled trial by Picchio et al ${ }^{[8]}$, who found similar incidence of chronic groin pain between ilioinguinal nerve excision group versus nerve preservation.

Much controversy exists regarding which treatment to be followed for the inguinal nerves during hernia repair. Lichtenstein et al recommend to always preserving the nerve to minimize the incidence of chronic pain.

Some studies recommend that ilioinguinal nerve should be intentionally divided to reduce the risk of chronic pain. Others have suggested that the nerves be excised only when their course, on the operating field, lead to the risk of injury or interfere with positioning of the mesh. 
Our study a prospective study showed a satisfactory significant decrease in the incidence of post-operative groin pain at 1 month, 6 months and 1 year for patients in the ilioinguinal nerve excision group versus nerve preservation group (16\% v/s $24 \%, 12.4 \%$ v/s $22.7 \%, 4.16 \%$ v/s $22.7 \%$ respectively).These differences were dramatic, with the incidence of pain up to 1 year post-operatively much lower in nerve excision group $(4.16 \%)$ versus the nerve preservation group $(22.7 \%)$.

Our study clearly demonstrated that, elective excision of ilioinguinal nerve not accompanied by a significant increase in post-operative numbness as depicted in table no.5. Furthermore, there was a consistent decrease in incidence of post-operative numbness with increasing time period in nerve excision group. At the end of 1 year, both groups are comparable $12.48 \%$ (nerve excision group) versus $9.08 \%$ (nerve preservation group). This may suggest progressive compensation from adjacent sensory nerve that could continue to improve over time.

The present study has several limitations

1. We were unable to perform clinical neurological examination at 6 months \& 1 year, for loss of pain \& touch sensation

2. Meaningful assessment of chronic pain at 1 month may not be possible in presence of early postoperative swelling, induration $\&$ pain.

3. Long term effect of ilioinguinal neurectomy was not followed up.

4. Although we are able to show that prophylactic neurectomy decreases the incidence of chronic groin pain, the exact reasoning behind this phenomenon remains unknown.

Longer clinical trials involving more patients and longer follow-up are warranted to study the long term effect of prophylactic ilioinguinal neurectomy in patients undergoing Lichtenstein hernia repair. Further histologic \& nerve conduction studies are required to explain the exact mechanism of decreasing the chronic pain by prophylactic neurectomy.

\section{Conclusion}

The result of this prospective trial demonstrates that prophylactic excision of ilioinguinal nerve during Lichtenstein tension free hernioplasty.

1. Significantly decreases the incidence of chronic groin pain after surgery.

2. Not associated with additional morbidities in terms of local cutaneous neurosensory disturbances.

3. Safe to perform.

4. Well tolerated by the patients.

5. High patient satisfaction in terms of no recurrence \& no pain.

So ilioinguinal neurectomy should be considered as a routine surgical step during open mesh hernia repairs.

\section{References}

1. Townsend Jr CM, Beauchamp RD, Evers BM, Mattox KL. Sabiston Textbook of Surgery. 19th. Ch 55.

2. Nienhuijs S, Staal E, Strobbe L, Rosman C, Groenewoud H, Bleichrodt R. Chronic pain after mesh repair of inguinal hernia: a systematic review. The American journal of surgery. 2007 Sep 1;194(3):394-400.

3. Bay-Nielsen M, Perkins FM, Kehlet $H$. Pain and functional impairment 1 year after inguinal herniorrhaphy: a nationwide questionnaire study. Annals of surgery. $2001 \mathrm{Jan} ; 233(1): 1$.

4. Fisher JE, Amid PK, Chen C. Postherniorrhaphy inguinodynia: causes, prevention, and surgical treatment: triple neurectomy. In: Fischer JE. Fisher's Mastery of Surgery. 6th Edition. Lippcott Williams and Wilkins. South Asian: 2012;21482153.

5. Poobalan AS, Bruce J, Smith WC, King PM, Krukowski ZH, Chambers WA. A review of chronic pain after inguinal 
herniorrhaphy. The Clinical journal of pain. 2003 Jan 1;19(1):48-54.

6. Geis WP, Sing K, Gillion GK. An Algorithm for the treatment of chronic pain after inguinal. Herniorrhaphy. 2002;307-16.

7. Cunningham W, Temple J, Mitchell P. Cooperative hernia study: pain in the postsurgical patient. Am J Surg. 1996;224:59802.

8. Picchio M, Marcello P, Palimento D. RCT of preservation or elective division of ilio inguinal nerve on open mesh repair. Arch Surg. 2004;139:755-8.

9. Poobalan AS, Bruce J, King PM. Chambers WA, Krukowski ZH, Smith WC Chronic pain and quality of life following open inguinal hernia repair. Br.JSurg 2001 Aug; 88 (8) 1122-6.

10. Bay-Nielsen M, Nilsson E, Nordin P, Kehlet H, Chronic Pain after open mesh \& Sutured repair of indirect inguinal hernia in young males. Br J Surg. 2004 Oct; 91(10): 1372-6.

11. Alfieris, Rotandi F, Diicelid et al. Chronic pain after inguinal hernias meslmulticentric study of 973 cases. Chir ital. 2006 Jan-Feb; 58 (1) : 23-31.

12. Dennis R, O'riordan D. Risk factors for chronic pain after inguinal hernia repair. The Annals of The Royal College of Surgeons of England. 2007 Apr;89(3):21820.

13. Courtney CA, Duffy K, Serpell MG, O'dwyer PJ. Outcome of patients with severe chronic pain following repair of groin hernia. British Journal of Surgery. 2002 Oct 1;89(10):1310-4.

14. Ravichandran D, Kalambe BG, Pain JA. Pilot randomized controlled study of preservation or division of ilioinguinal nerve in open mesh repair of inguinal hernia. British journal of surgery. 2000 Sep 1;87(9):1166-7.
15. Tsakayannis DE, Kiriakopoulos AC, Linos DA. Elective neurectomy during open, "tension free" inguinal hernia repair. Hernia. 2004 Feb 1;8(1):67-9.

16. Wantz GE. Testicular atrophy and chronic residual neuralgia as risks of inguinal hernioplasty. Surgical Clinics of North America. 1993 Jun 1;73(3):571-81.

17. Bansal A, Rabha S, Griwan M, Karthikeyan Y. Comparative evaluation of preservation versus elective division of the ilioinguinal nerve in open mesh repair of inguinal hernias. The Internet Journal of Surgery. 2013;30(1).

18. Mulkipatil SY, Kuntoji SB. Randomized control study of ilio-inguinal nerve preservation versus neurectomy in lichtenstein tension free mesh repair of inguinal hernia. International Surgery Journal. 2016 Dec 13;4(1):209-13.

19. Belagali H, Manjunath DA, Devani R, Radhakrishna V. Prophylactic ilioinguinal neurectomy in open inguinal hernia repair: a randomized control trial. International Surgery Journal. 2018 Feb 26;5(3):904-7. 